\title{
LIVER DISEASE
}

\section{The role of the transjugular intrahepatic portosystemic stent shunt (TIPSS) in the management of bleeding gastric varices: clinical and haemodynamic correlations}

\author{
D Tripathi, G Therapondos, E Jackson, D N Redhead, P C Hayes
}

Gut 2002;51:270-274

\begin{abstract}
Background: The transjugular intrahepatic portosystemic stent shunt (TIPSS) is effective in the management of both oesophageal and gastric variceal bleeding. Although it has been reported that gastric varices can bleed at pressures of $\leqslant 12 \mathrm{~mm} \mathrm{Hg}$, this phenomenon has been little studied in the clinical setting.

Aims: To assess the efficacy of TIPSS on rebleeding and mortality following gastric and oesophageal variceal bleeding, and the importance of portal pressure in both groups.

Methods: Forty eligible patients who had bled from gastric varices and 232 from oesophageal varices were studied. Patients were also subdivided into those whose portal pressure gradients (PPG) prior to TIPSS were $\leqslant 12 \mathrm{~mm} \mathrm{Hg}$ (group 1) and $>12 \mathrm{~mm} \mathrm{Hg}$ (group 2).

Results: There was no difference in Child-Pugh score, age, sex, or alcohol related disease between patients bleeding from gastric or oesophageal varices. Patients who bled from gastric varices had a lower PPG pre-TIPSS $(15.8(0.8) \vee 21.44(0.4) \mathrm{mm} \mathrm{Hg} ; \mathrm{p}<0.001)$. There was no difference in the rebleeding rate $(20.0 \%$ v $14.7 \%$; NS). There was a significant difference $(p<0.05)$ in favour of the gastric varices group in the one year mortality $(30.7 \%$ v $38.7 \%)$ and five year mortality $(49.5 \% \mathrm{v}$ $74.9 \%$, particularly in those patients in group 2. Gastric variceal bleeding accounted for significantly more cases in group 1 than in group $2(36.8 \%$ v 10.2\%; p<0.001). Most patients in group 2 who rebled had a PPG post-TIPSS of $>7 \mathrm{~mm} \mathrm{Hg}$.

Conclusions: TIPSS is equally effective in the prevention of rebleeding following gastric and oesophageal variceal bleeding. A significant proportion of gastric varices bleed at a PPG $\leqslant 12 \mathrm{~mm} \mathrm{Hg}$. The improved mortality in patients with gastric variceal bleeding is seen only in those that bleed at a PPG $>12 \mathrm{~mm} \mathrm{Hg}$, and warrants further study.
\end{abstract}

See end of article for authors' affiliations

V ariceal haemorrhage is a major cause of mortality and morbidity in patients with cirrhosis and portal hypertension. ${ }^{1}$ Studies have reported an association between portal pressure and the risk of variceal bleeding. ${ }^{23}$ It has been reported that varices rarely bleed if the portal pressure gradient (PPG) is less than $12 \mathrm{~mm} \mathrm{Hg}$ and many advocate this as a therapeutic goal. ${ }^{4}$

The management of bleeding gastric varices has been a particular challenge to clinicians. It is known that the natural history of bleeding gastric varices differs from that of oesophageal varices. Although the risk of bleeding from gastric varices is less than that of oesophageal varices, the outcome once bleeding has occurred is worse, particularly for isolated gastric varices. ${ }^{5}$ Various endoscopic methods, including standard sclerotherapy ${ }^{6}$ and injection of tissue adhesives, ${ }^{7}$ have resulted in good initial haemostasis but are limited by a high rebleeding rate. Results using thrombin are more promising in uncontrolled studies. ${ }^{8}{ }^{9}$ The use of a transjugular intrahepatic portosystemic stent shunt (TIPSS) has been studied extensively for oesophageal variceal bleeding (OVB) and more recently for the management of gastric variceal bleeding (GVB). We have previously shown TIPSS to be equally effective in the management of gastric varices, a finding which has been confirmed by other centres, particularly in emergency or refractory GVB. ${ }^{10-12}$

Despite reports that varices bleed almost exclusively at portal pressures of greater than $12 \mathrm{~mm} \mathrm{Hg},{ }^{4}$ we have shown previously that a minority of patients with directly measured PPG $<12 \mathrm{~mm} \mathrm{Hg}$ remain at risk of variceal bleeding. ${ }^{13}$ Furthermore, it is recognised that gastric varices occur at lower portal pressures than oesophageal varices. ${ }^{14}$
The aim of this study was to analyse retrospectively the clinical outcome of patients who have bled from gastric varices and in whom a TIPSS procedure was undertaken. These patients were compared with a group of patients who bled from oesophageal varices. Haemodynamic and clinical correlations were made, and patients who bled at a PPG of $\leqslant 12 \mathrm{~mm}$ $\mathrm{Hg}$ were studied to identify whether they differed from the group who bled at higher portal pressures with regard to site of variceal bleed, rebleeding, and survival.

\section{PATIENTS AND METHODS \\ Patients}

During the period between September 1991 and August 2000, 436 patients underwent a TIPSS procedure in our centre. In 377 patients the primary indication was variceal haemorrhage with the remainder having ascites $(n=44)$, portal hypertensive gastropathy $(n=9)$, or other indication $(n=6)$. Patients were excluded if the TIPSS procedure had failed $(n=24)$, if they had participated in a trial comparing TIPSS versus TIPSS and banding and were randomised to the TIPSS and banding arm (where TIPSS angiographic surveillance was performed for the first year after TIPSS only, $n=40$ ), or if there were insufficient data $(n=21)$. After exclusions there were a total of 292 patients from which the study populations were selected.

Abbreviations: TIPSS, transjugular intrahepatic portosystemic stent shunt; PPG, portal pressure gradient; GVB, gastric variceal bleeding; OVB, oesophageal variceal bleeding; HVPG, hepatic venous pressure gradient. 
Table 1 Baseline characteristics of the patients

\begin{tabular}{|c|c|c|c|c|c|}
\hline & $\begin{array}{l}\text { Gastric varices } \\
(n=40)\end{array}$ & $\begin{array}{l}\text { Oesophageal } \\
\text { varices }(n=232)\end{array}$ & $\begin{array}{l}\text { Gastric and } \\
\text { oesophageal } \\
\text { varices }(n=12)\end{array}$ & \multicolumn{2}{|c|}{$\begin{array}{l}\text { Ectopic varices } \\
(n=8)\end{array}$} \\
\hline Age $(y)$ & $50.9(1.6)$ & $53.6(0.8)$ & $45.4(5.4)$ & 52.5 & (4.0) \\
\hline \multicolumn{6}{|l|}{ Sex } \\
\hline Male & $(55.0 \%)$ & $150 \quad(64.7 \%)$ & $(50 \%)$ & 4 & $(50 \%)$ \\
\hline Female & $(45.0 \%)$ & $82 \quad(35.3 \%)$ & $(50 \%)$ & 4 & $(50 \%)$ \\
\hline \multicolumn{6}{|l|}{ Aetiology } \\
\hline Alcoholic liver disease & $(70.0 \%)$ & $140 \quad(60.3 \%)$ & $(41.8 \%)$ & 5 & $(62.5 \%)$ \\
\hline Primary biliary cirrhosis & $1 \quad(2.5 \%)$ & $2 \quad(12.1 \%)$ & $(8.3 \%)$ & 0 & \\
\hline Hepatitis C & $1 \quad(2.5 \%)$ & $16 \quad(6.9 \%)$ & $(16.7 \%)$ & 0 & \\
\hline Cryptogenic cirrhosis & $7 \quad(17.5 \%)$ & $18(7.8 \%)^{* *}$ & $(8.3 \%)$ & 1 & $(12.5 \%)$ \\
\hline Autoimmune & $1 \quad(2.5 \%)$ & $8 \quad(3.4 \%)$ & 0 & 0 & \\
\hline Cystic fibrosis & 0 & $5 \quad(2.2 \%)$ & (8.3\%) & 0 & \\
\hline Primary sclerosing cholangitis & $1 \quad(2.5 \%)$ & $4 \quad(1.7 \%)$ & (8.3\%) & 2 & $(25 \%)$ \\
\hline Hepatitis B & $1 \quad(2.5 \%)$ & $4 \quad(1.7 \%)$ & $(8.3 \%)$ & 0 & \\
\hline Other & 0 & $9 \quad(3.9 \%)$ & 0 & 0 & \\
\hline Child-Pugh score & $9.3(0.5)$ & $9.8(0.2)$ & $9.3(0.7)$ & 10.9 & (0.9) \\
\hline \multicolumn{6}{|l|}{ Portal pressure gradient $(\mathrm{mm} \mathrm{Hg})$} \\
\hline Pre-TIPSS & $15.8(0.8)$ & $21.4(0.5)^{* *}$ & $22.5(3.0)^{*}$ & 15.6 & $(2.5)$ \\
\hline Post-TIPSS & $6.7(0.6)$ & $7.2(0.3)$ & $7.1(1.4)$ & 6.9 & (1.9) \\
\hline Reduction post-TIPSS & $9.2(0.8)$ & $14.2(0.5)^{* *}$ & $15.4(3.5)^{*}$ & 8.8 & (2.1) \\
\hline Median follow up (months) & $36.7(5.1)$ & $19.8(1.3)^{* *}$ & $16.8(5.1)$ & 8.1 & $(4.9)^{*}$ \\
\hline
\end{tabular}

\begin{tabular}{|c|c|c|c|c|c|}
\hline & $\begin{array}{l}\text { Grou } \\
(n=3\end{array}$ & $\begin{array}{l}\text { p } 1 \\
8)\end{array}$ & $\begin{array}{l}\text { Group } \\
(n=254\end{array}$ & & $\mathrm{p}$ Value \\
\hline Age (y) & 54.9 & (1.9) & 52.5 & $(0.8)$ & NS \\
\hline \multicolumn{6}{|l|}{ Sex } \\
\hline Male & 25 & $(65.8 \%)$ & 157 & (61.8\%) & NS \\
\hline Female & 13 & $(34.2 \%)$ & 97 & $(38.2 \%)$ & NS \\
\hline \multicolumn{6}{|l|}{ Aetiology } \\
\hline Alcoholic liver disease & 27 & $(71.1 \%)$ & 151 & $(59.4 \%)$ & NS \\
\hline Primary biliary cirrhosis & 3 & (7.9) & 27 & $(10.6 \%)$ & NS \\
\hline Hepatitis C & 0 & & 20 & $(7.9 \%)$ & NS \\
\hline Cryptogenic cirrhosis & 5 & $(13.2 \%)$ & 23 & (9.1\%) & NS \\
\hline Autoimmune & 1 & $(2.6 \%)$ & 8 & (3.1\%) & NS \\
\hline Cystic fibrosis & 0 & & 6 & $(2.4 \%)$ & NS \\
\hline Primary sclerosing cholangitis & 1 & $(2.6 \%)$ & 7 & $(2.8 \%)$ & NS \\
\hline Hepatitis B & 1 & $(2.6 \%)$ & 3 & $(1.2 \%)$ & NS \\
\hline Other & 0 & & 9 & (3.5\%) & NS \\
\hline \multicolumn{6}{|l|}{ PPG $(\mathrm{mm} \mathrm{Hg})$} \\
\hline Pre-TIPSS & 9.8 & $(0.4)$ & 22.1 & (0.4) & $<0.001$ \\
\hline Post-TIPSS & 4.2 & $(0.5)$ & 7.6 & (0.3) & $<0.05$ \\
\hline Reduction post-TIPSS & 5.6 & $(0.5)$ & 14.6 & $(0.5)$ & $<0.001$ \\
\hline Child-Pugh score & 9.1 & $(0.5)$ & 9.9 & $(0.2)$ & NS \\
\hline \multicolumn{6}{|l|}{ Indication } \\
\hline Oesophageal variceal bleeding & 20 & $(52.6 \%)$ & 212 & $(83.5 \%)$ & $<0.001$ \\
\hline Gastric variceal bleeding & 14 & $(36.8 \%)$ & 26 & $(10.2 \%)$ & $<0.001$ \\
\hline Gastric and oesophageal variceal bleeding & 2 & $(5.3 \%)$ & 10 & $(3.9 \%)$ & NS \\
\hline Ectopic variceal bleeding & 2 & $(5.3 \%)$ & 6 & $(2.4 \%)$ & NS \\
\hline
\end{tabular}

In the eligible patients, 40 patients had a TIPSS performed for GVB, 232 for OVB alone, 12 for both GVB and OVB, and eight for ectopic variceal bleeding. All varices were thought to have arisen because of portal hypertension secondary to parenchymal liver disease. In 38 cases of GVB, bleeding was believed to have been from varices in the fundus or cardia, and two cases from varices along the lesser curve. Table 1 illustrates the baseline characteristics of these patients. There were more patients with cryptogenic cirrhosis in the OVB group.

In order to make haemodynamic and clinical correlations, patients were further divided into two groups according to the direct PPG at the time of TIPSS. Group 1 included those patients with $\mathrm{PPG} \leqslant 12 \mathrm{~mm} \mathrm{Hg}(\mathrm{n}=38)$ and group 2 those patients with a PPG >12 mm Hg $(\mathrm{n}=254)$. The baseline characteristics of these patients are detailed in table 2 . There was no difference in the age, sex, aetiology of liver disease, or Child-Pugh score between the two groups.

\section{TIPSS procedure}

All patients were referred for TIPSS from within the Royal Infirmary, Edinburgh, or from other hospitals within Scotland. Our unit operates a 24 hour facility for emergency TIPSS insertion. TIPSS insertion was performed by an experienced radiologist using an established technique. ${ }^{15}$ Where the original pressure was >12 mm Hg, the aim was to reduce the PPG to below $12 \mathrm{~mm} \mathrm{Hg}$. The patency of the TIPSS shunt was assessed by Doppler ultrasound within a week of insertion, 


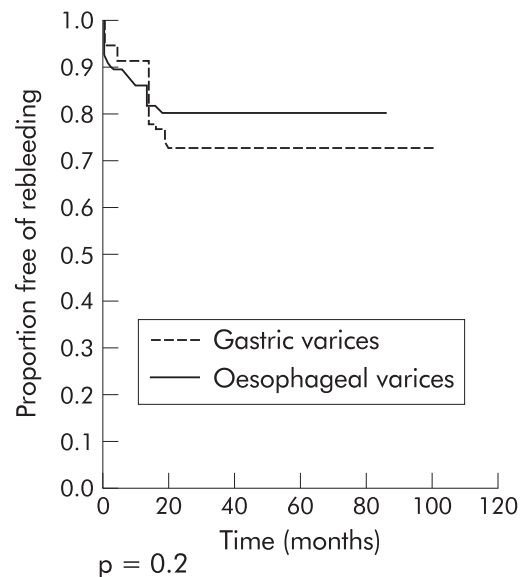

$\begin{array}{lcccccccc}\text { Time (months) } & 0 & 10 & 20 & 30 & 40 & 50 & 60 \\ & \text { months } & \text { months } & \text { months } & \text { months } & \text { months } & \text { months } & \text { months } \\ \begin{array}{l}\text { Gastric } \\ \text { varices }\end{array} & 40 & 25 & 17 & 17 & 15 & 14 & 9 \\ \begin{array}{l}\text { Oesophageal } \\ \text { varices }\end{array} & 232 & 114 & 85 & 52 & 37 & 22 & 6\end{array}$

Figure 1 Kaplan Meier graph of rebleeding for all patients who bled from gastric and oesophageal varices treated with a transjugular intrahepatic portosystemic stent shunt.

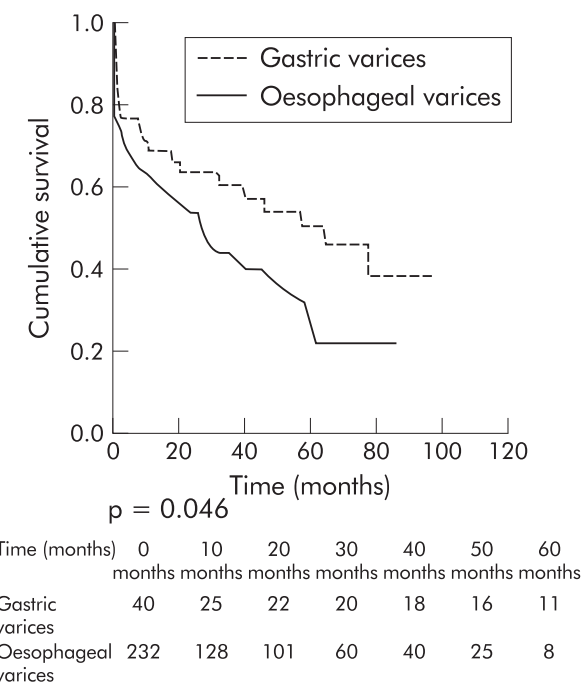

Figure 2 Kaplan Meier graph of survival for all patients who bled from gastric and oesophageal varices treated with a transjugular intrahepatic portosystemic stent shunt.

and by portogram at three months then six monthly thereafter or whenever there were clinical features suggestive of shunt insufficiency.

\section{Follow up}

Patients were followed up clinically at three monthly intervals to assess their clinical condition with emphasis being placed on any episodes of encephalopathy and variceal rebleeding. Early mortality was defined as death within four weeks of the variceal haemorrhage. Variceal rebleeding was defined as subsequent variceal bleeding manifested by haematemesis and/or melaena, requiring an unscheduled endoscopy, and accompanied by a reduction in haemoglobin concentration by $20 \mathrm{~g} / \mathrm{l}$ or more. Shunt insufficiency (defined as an increase in PPG $\geqslant 12$ $\mathrm{mm} \mathrm{Hg}$ or a $20 \%$ rise above the immediate post-TIPSS PPG) was assessed based on the results of routine follow up angiographic surveillance. Any episodes of shunt insufficiency were treated by balloon angioplasty, shunt extension, or parallel shunt placement, as required to maintain patency. Follow up time was defined as the time interval in months between the initial TIPSS insertion to either the most recent clinic review, liver transplantation, or death.

\section{Statistical analysis}

All results are expressed as mean (SEM) or percentage, where indicated. Statistical significance for parametric data was determined using Student $t$ tests, and for non-parametric data using the $\chi^{2}$ and Mann Whitney $U$ tests. The Kaplan-Meier method was used to analyse patient survival, and cumulative rebleeding risk, with comparison between the two groups, was determined by the log rank test. Univariate and multivariate relations between survival and variables of interest in those patients who bled from gastric varices and oesophageal varices at a PPG >12 mm Hg was performed using Cox regression analysis. These variables were: aetiology of cirrhosis (alcoholic or non-alcoholic), site of bleeding (from gastric or oesophageal varices), sex and age of the patients, encephalopathy, ascites, bilirubin, prothrombin time, albumin, and the time interval between the index bleed and TIPSS insertion. Significance was taken at $\mathrm{p}<0.05$ for all tests. All statistical analysis was performed using the SPSS package (version 10; SPSS Inc., Chicago, Illinois, USA).

\section{RESULTS}

\section{PPG before and after TIPSS}

PPG pre-TIPSS was significantly higher in patients who bled from oesophageal varices compared with GVB (21.4 (0.5) $v$ $15.8(0.8) \mathrm{mm} \mathrm{Hg} ; \mathrm{p}<0.001)$. Following TIPSS insertion, all patients who had bled from gastric varices had PPG reduced to $<12 \mathrm{~mm} \mathrm{Hg}$, while in $22(9.5 \%)$ patients who bled from oesophageal varices the post-TIPSS PPG was $>12 \mathrm{~mm} \mathrm{Hg}$. However, mean PPG post-TIPSS was similar in the GVB and OVB groups (table 1).

\section{Rebleeding}

The mean follow up period was 19.8 (1.3) and 36.7 (5.1) months in the OVB and GVB groups, respectively $(\mathrm{p}<0.01)$. The longer follow up time in the GVB group may reflect the greater proportion of patients recruited in or prior to 1995 compared with the OVB group $(62.5 \% v 29.7 \% ; p<0.001)$. In this time, $34(14.7 \%)$ patients in the OVB group rebled and eight $(20 \%)$ patients in the GVB group rebled. The cumulative risk of rebleeding was similar in both groups (fig 1). In 31 $(73.5 \%)$ cases of variceal rebleeding there was evidence of TIPSS dysfunction.

\section{Mortality}

During this follow up period there was a significant difference in the cumulative risk of death in favour of the GVB group $(\mathrm{p}<0.05$ by Kaplan-Meier method). This was true for 30 day mortality ( $15 \% \vee 23.8 \%)$, one year mortality $(30.7 \% v 38.6 \%)$, and five year mortality (49.5\% v 74.9\%) (fig 2). There was no significant difference in the time interval to TIPSS from the variceal bleed $(5.4(0.9)$ days $v 4.9(0.4)$ days for the GVB and OVB groups, respectively; NS). The principal cause of death was similar in both groups, with liver failure or sepsis accounting for $82(64.1 \%)$ deaths in the OVB group and 12 (75\%) deaths in the GVB group.

\section{Encephalopathy}

The rate of encephalopathy prior to TIPSS insertion was similar in the OVB and GVB groups ( $27.6 \%$ v $30.0 \%$; NS). There was no significant difference in episodes of new or worsening encephalopathy in the oesophageal and gastric varices groups (16.35\% $v 17.5 \%$ respectively; NS) All episodes of encephalopathy were managed initially with lactulose and protein reduction. In three cases the shunt was reduced in size, and in eight cases it was necessary to block the shunt with a filter with or without coils. 


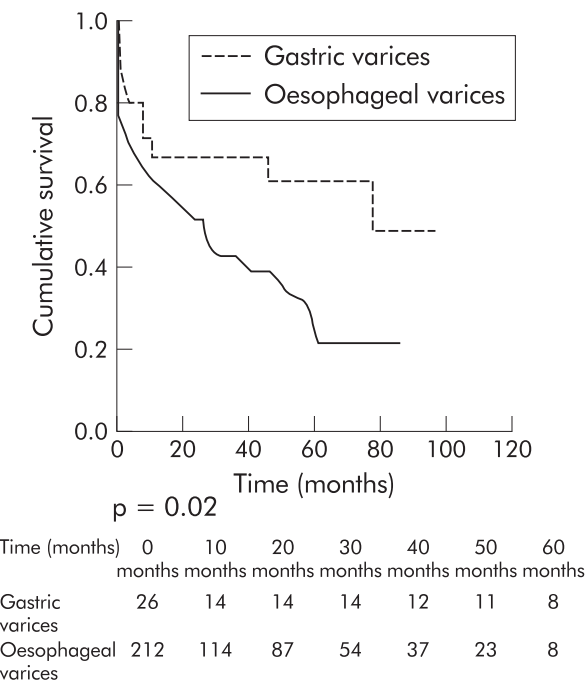

Figure 3 Kaplan Meier graph of survival for all patients who bled from gastric and oesophageal varices at a portal pressure gradient of greater than $12 \mathrm{~mm} \mathrm{Hg}$.

\section{Shunt insufficiency}

There was no difference in the incidence of shunt insufficiency between the two groups $(42.67 \% v 55 \%$ in the OVB and GVB groups, respectively). In one patient in the GVB group problems with maintaining TIPSS patency resulted in elective surgery with the creation of a distal splenorenal shunt.

\section{Orthotopic liver transplantation}

Twenty one patients required an orthotopic liver transplantation, $19(8.2 \%)$ in the oesophageal varices group and two $(5 \%)$ in the gastric varices group (NS).

\section{Correlations between portal pressure and clinical outcome}

When patients with a pre-TIPSS PPG $\leqslant 12 \mathrm{~mm} \mathrm{Hg}$ were analysed, it was clear that GVB accounted for many more cases than for those patients who bled at a PPG > $12 \mathrm{~mm} \mathrm{Hg}(36.8 \%$ $v 10.2 \% ; \mathrm{p}<0.001$ ) (table 2). However, there was no overall difference in the rebleeding rate and mortality in the two groups. Rates of shunt insufficiency and encephalopathy were also similar in the two groups. In group 1, the final PPG postTIPSS was similar in those patients that rebled $(n=9)$ compared with those that did not rebleed $(n=29)(5.1(0.1)$ $\mathrm{mm} \mathrm{Hg}$ and $3.9(0.5) \mathrm{mm} \mathrm{Hg}$, respectively; $\mathrm{p}=0.2$ ). In group 2, PPG post-TIPSS was significantly higher in patients who rebled post-TIPSS $(n=35)$ compared with those that did not rebleed $(\mathrm{n}=219)(9.4(0.8) \mathrm{mm} \mathrm{Hg}$ and $7.3(0.3) \mathrm{mm} \mathrm{Hg}$, respectively; $\mathrm{p}<0.005)$. In addition, $75 \%$ of patients in group 2 who rebled had a PPG post-TIPSS of $>7 \mathrm{~mm} \mathrm{Hg}$.

When patients who bled from either oesophageal varices or gastric varices with a PPG pre-TIPSS of $>12 \mathrm{~mm} \mathrm{Hg}$ were analysed, there was a significant difference in mortality in favour of gastric varices ( $p=0.02$ by Kaplan-Meier method). Thirty day mortality ( $12 \% \vee 24.2 \%)$, one year mortality $(33.8 \%$ $v 40.4 \%)$, and five year mortality $(39.4 \% v 79.1 \%)$ were all significantly better in the gastric varices group (fig 3). Univariate analysis showed that the following variables were associated with higher mortality in patients who bled from gastric or oesophageal varices at a PPG $>12 \mathrm{~mm} \mathrm{Hg}$ : increasing age $(p<0.01)$, bleeding from oesophageal varices $(p=0.04)$, high prothrombin time $(p<0.05)$, high bilirubin $(p<0.001)$, low albumin $(p=0.001)$, presence of ascites $(p<0.001)$, and encephalopathy $(p<0.05)$. Multivariate analysis of these variables revealed that older age of patients $(p<0.05)$, high bilirubin $(p<0.05)$, and a low albumin $(p<0.001)$ were independent variables predicting mortality. There was no differ- ence in the rebleeding rate. Mortality and rebleeding rates were similar in the GVB and OVB groups who bled at a PPG $\leqslant 12 \mathrm{~mm} \mathrm{Hg}$.

\section{DISCUSSION}

Historically, the management of GVB has been suboptimal. Endoscopic measures have met with varying degrees of success $^{6}$ although current UK guidelines recommend endoscopic treatment as the first line in the management of the acute gastric variceal bleed..$^{7-9} 1617$ Iatrogenic complications such as embolic phenomena and the potential for equipment damage may limit the use of tissue adhesives. ${ }^{18}{ }^{19}$ Thrombin seems to be promising but large multicentre controlled trials have yet to emerge. Previous studies have used bovine thrombin which has the potential risk of prion transmission $^{89}$ although our experience with human thrombin has been promising so far. ${ }^{20}$ Surgical shunts may be of value in patients with early liver disease ${ }^{21-23}$ but have the disadvantage of high mortality in patients with advanced liver disease, particularly in the emergency setting. ${ }^{24}$

Our findings show that TIPSS is equally effective in the prevention of rebleeding from gastric and oesophageal variceal haemorrhage. Incidences of shunt insufficiency and encephalopathy were similar in both groups. These results are similar to those of an earlier study in our unit. ${ }^{12}$ We have adopted a policy of referring patients with bleeding gastric varices and a patent portal vein directly for TIPSS insertion. A further finding is the significant numbers of patients that bleed at a PPG of $<12 \mathrm{~mm} \mathrm{Hg}$, and gastric varices account for a sizeable proportion of this group.

It has been reported that patients with large gastric varices have a lower portal pressure than those with oesophageal varices, ${ }^{25}$ which may be as a result of the development of gastro-renal porto-systemic shunts. ${ }^{14}$ Watanabe et al also demonstrated increased collateral flow at the expense of reduced portal venous flow in patients with gastric varices. The authors proposed that reduced portocollateral resistance may account for the latter finding. It is however unclear as to why patients bleed at portal pressures of $<12 \mathrm{~mm} \mathrm{Hg}$. Other factors such as the presence of red spots, variceal size, and that of gastritis may be important. Therefore, particularly in patients with gastric varices, it would not be safe to regard reducing a PPG of $<12 \mathrm{~mm} \mathrm{Hg}$ as a therapeutic goal. Indeed, for patients who bleed at a PPG $\leqslant 12 \mathrm{~mm} \mathrm{Hg}$, our results demonstrate that PPG post-TIPSS is not statistically different in patients who rebleed compared with those that do not. However, for patients who bleed at a PPG $>12 \mathrm{~mm} \mathrm{Hg}$, the post-TIPSS PPG is greater for patients who rebleed, with most of these patients having a PPG post-TIPSS of $>7 \mathrm{~mm} \mathrm{Hg}$. These results suggest that in group 2 (that is, predominantly oesophageal variceal bleeders) a therapeutic goal of a post-TIPSS PPG $<7 \mathrm{~mm} \mathrm{Hg}$ would be reasonable.

TIPSS has recently been studied in the management of refractory variceal bleeding either from gastric alone ${ }^{11}$ or gastric compared with oesophageal varices. ${ }^{26}{ }^{27}$ Our rebleeding rates are comparable with these studies. Chau et al also found that portal pressure in patients who had early rebleeding before seven days was lower in patients with GVB. ${ }^{26}$ Rees and

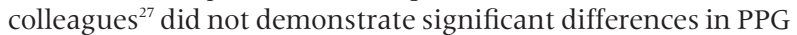
prior to TIPSS which was $>20 \mathrm{~mm} \mathrm{Hg}$ in both groups. This study was limited by a small number of patients and a short follow up period.

An interesting finding in the present study is that of significantly better survival in the GVB group compared with the OVB group, despite the two groups being matched for age, aetiology of liver disease, Child-Pugh score, and pre-TIPSS encephalopathy. We have previously shown the latter two parameters to strongly predict mortality post-TIPSS. ${ }^{28}$ It has also been observed that mortality following a variceal haemorrhage is highest in the first few days after the index 
bleed. ${ }^{29}$ Both the OVB and GVB groups were matched for the time of intervention with TIPSS after the variceal bleed and thus there was no undue selection of patients in either group who were likely to have a better survival. The difference in mortality between the two groups appears to be confined to patients who bleed at a PPG $>12 \mathrm{~mm} \mathrm{Hg}$, and is particularly striking for long term mortality. Older age of the patient, high bilirubin, and low albumin in keeping with more advanced liver disease were independent predictors of mortality. The causes of death in both groups were predominantly liver failure and sepsis. The earlier study in our unit ${ }^{12}$ had demonstrated a trend towards improved survival among the GVB group. The present study had a greater number of patients and a longer follow up period, which may account for the now significant findings. The longer follow up period in the GVB group is likely to be a result of the combination of reduced mortality and larger numbers of patients recruited before or in 1995 .

It is important to highlight the observation of a significantly higher PPG prior to TIPSS insertion in patients with OVB. We have previously shown that a hepatic venous pressure gradient (HVPG) of $>16 \mathrm{~mm} \mathrm{Hg}$ predicted mortality in patients with alcoholic cirrhosis. ${ }^{30}$ This finding was reinforced in a later study by Patch and colleagues. ${ }^{31}$ HVPG measurements made within the first or second week had the greatest predictive value. Nearly all of our patients had their portal pressures measured at the time of TIPSS within the first two weeks of the index variceal bleed. A recent study by Moitinho and colleagues ${ }^{32}$ assessed the prognostic value of early portal pressure measurements following an acute variceal bleed. The striking finding in this study was that patients with a HVPG of $>20 \mathrm{~mm} \mathrm{Hg}$ had a one year mortality of $64 \%$ compared with $20 \%$ for that of patients with HVPG $<20 \mathrm{~mm} \mathrm{Hg}(\mathrm{p}<0.004)$. In our group, all patients who bled from oesophageal varices had a mean PPG $>21 \mathrm{~mm} \mathrm{Hg}$. It is therefore plausible that the difference in PPG between the OVB and GVB groups may account for the difference in the observed mortality, although the reason why PPG affects mortality is not understood. We have not shown a difference in rebleeding rates as the rebleeding rate was so low in both groups following TIPSS insertion that much larger numbers may be needed to show any differences. This illustrates the impressive efficacy of TIPSS in preventing variceal rebleeding.

In conclusion, our study demonstrates that TIPSS is very effective in the prevention of variceal rebleeding irrespective of whether patients have had an OVB or a GVB. Mortality is significantly better in the GVB group who bleed at a PPG $>12$ $\mathrm{mm} \mathrm{Hg}$, and warrants further study. The findings also highlight the significant role of GVB in patients who bleed at a PPG $\leqslant 12 \mathrm{~mm} \mathrm{Hg}$, and challenges the use of this cut off value as a treatment goal, particularly in patients with gastric varices. Our results also suggest that clinicians should aim for a PPG post-TIPSS of $<7 \mathrm{~mm} \mathrm{Hg}$ for patients who have variceal bleeding at a PPG $>12 \mathrm{~mm} \mathrm{Hg}$. TIPSS therefore has a major role in the management of GVB, which can be very difficult to control by other measures. Further long term prospective studies would assist in clarifying the effect of TIPSS on mortality in the GVB group compared with OVB.

\section{ACKNOWLEDGMENTS}

We would like to thank Dr N D C Finlayson, Dr A J MacGilchrist, and Dr K J Simpson for their support with the study. We also wish to acknowledge the administrative assistance of research nurses Sister Kim Macbeth and Sister Gwenyth Wilkie in data collection and arranging clinical follow up.

\section{Authors' affiliations}

D Tripathi, G Therapondos, P C Hayes, Centre for Liver and Digestive Disorders and Department of Medicine, Royal Infirmary of Edinburgh, UK E Jackson, Medical School, University of Edinburgh, UK

D N Redhead, Department of Radiology, Royal Infirmary, Edinburgh, UK

\section{REFERENCES}

1 Williams SG, Westaby D. Management of variceal haemorrhage. BM 1994;308:1213-17.

2 Garcia-Tsao G, Groszmann R, Fisher RL, et al. Portal pressure presence of gastroesophageal varices and variceal bleeding. Hepatology 1985;5:419-24.

3 Feu F, Garcia-Pagan JC, Bosch J, et al. Relation between portal pressure response to pharmacotherapy and risk of recurrent variceal haemorrhage in patients with cirrhosis. Lancet 1995;346:1056-9.

4 Groszmann RJ, Bosch J, Grace ND, et al. Hemodynamic events in a prospective randomized trial of propranolol versus placebo in the prevention of a first variceal hemorrhage. Gastroenterology 1990;99:1401-7

5 Sarin SK, Lahoti D, Saxena SP, et al. Prevalence, classification and natural history of gastric varices: a long-term follow-up study in 568 portal hypertension patients. Hepatology 1992;16:1343-9.

6 Gimson AE, Westaby D, Williams R. Endoscopic sclerotherapy in the management of gastric variceal haemorrhage. J Hepatol 1991;13:274-8.

7 Ramond MJ, Valla D, Gotlib JP, et al. Endoscopic obturation of esophagogastric varices with bucrylate. I. Clinical study of 49 patients. Gastroenterol Clin Biol 1986:10:575-9.

8 Przemioslo RT, McNair A, Williams R. Thrombin is effective in arresting bleeding from gastric variceal hemorrhage. Dig Dis $\mathrm{Sci}$ 1999;44:778-81

9 Williams SG, Peters RA, Westaby D. Thrombin-an effective treatment for gastric variceal haemorrhage. Gut 1994;35:1287-9.

10 Albillos A, Ruiz dA. "Salvage" transjugular intrahepatic portosystemic shunt: gastric fundal compared with esophageal variceal bleeding. Gastrointest Endosc 1999;50:294-5.

11 Barange K, Peron JM, Imani K, et al. Transjugular intrahepatic portosystemic shunt in the treatment of refractory bleeding from ruptured gastric varices. Hepatology 1999:30:1 139-43.

12 Stanley AJ, Jalan R, Ireland HM, et al. A comparison between gastric and oesophageal variceal haemorrhage treated with transjugular intrahepatic portosystemic stent shunt (TIPSS). Aliment Pharmacol Ther 1997; 1 1:171-6.

13 Jalan R, Redhead DN, Forrest EH, et al. Relationship between directly measured portal pressure gradient and variceal hemorrhage. Am J Gastroenterol 1995;90:1994-6.

14 Watanabe K, Kimura K, Matsutani S, et al. Portal hemodynamics in patients with gastric varices. A study in 230 patients with esophageal and/or gastric varices using portal vein catheterization. Gastroenterology 1988;95:434-40.

15 Chalmers N, Redhead DN, Simpson KJ, et al. Transjugular intrahepatic portosystemic stent shunt (TIPSS): early clinical experience. Clin Radiol 1992;46:166-9

16 Jalan $\mathbf{R}$, Hayes PC. UK guidelines on the management of variceal haemorrhage in cirrhotic patients. British Society of Gastroenterology. Gut 2000;46(suppl 3-4):iii 1-15.

17 Takeuchi M, Nakai Y, Syu A, et al. Endoscopic ligation of gastric varices. Lancet 1996;348:1038

18 Lee GH, Kim JH, Lee KJ, et al. Life-threatening intraabdominal arterial embolization after histoacryl injection for bleeding gastric ulcer. Endoscopy 2000;32:422-4.

19 See A, Florent C, Lamy P, et al. Cerebrovascular accidents after endoscopic obturation of esophageal varices with isobutyl-2-cyanoacrylate in 2 patients. Gastroenterol Clin Biol 1986;10:604-7.

20 Yang WL, Tripathi D, Therapondos G, et al. Thrombin in gastric varices. Gut 2001;48(suppl 1):393.

21 Henderson JM, Nagle A, Curtas S, et al. Surgical shunts and tips for variceal decompression in the 1990s. Surgery 2000;1 28:540-7.

22 Orozco H, Mercado MA, Granados GJ, et al. Selective shunts for portal hypertension: current role of a 21 -year experience. Liver Transp/ Surg 1997; 3:475-80.

23 Thomas PG, D'Cruz AJ. Distal splenorenal shunting for bleeding gastric varices. BrJ Surg 1994;81:241-4

24 Krahenbuhl L, Seiler CA, Buchler MW. Variceal hemorrhage in portal hypertension: role of surgery in the acute and elective situation. Schweiz Med Wochenschr 1999;129:631-8.

25 Chao Y, Lin HC, Lee FY, et al. Hepatic hemodynamic features in patients with esophageal or gastric varices. J Hepatol 1993;19:85-9.

26 Chau TN, Patch D, Chan YW, et al. "Salvage" transjugular intrahepatic portosystemic shunts: gastric fundal compared with esophageal variceal bleeding. Gastroenterology 1998;114:981-7.

27 Rees CJ, Nylander DL, Thompson NP, et al. Do gastric and oesophageal varices bleed at different portal pressures and is TIPS an effective treatment? Liver 2000;20:253-6.

28 Jalan R, Elton RA, Redhead DN, et al. Analysis of prognostic variables in the prediction of mortality, shunt failure, variceal rebleeding and encephalopathy following the transjugular intrahepatic portosystemic stent-shunt for variceal haemorrhage. J Hepatol 1995;2:123-8.

29 Smith JL, Graham DY. Variceal hemorrhage: a critical evaluation of survival analysis. Gastroenterology 1982;82:968-73.

30 Stanley AJ, Robinson I, Forrest EH, et al. Haemodynamic parameters predicting variceal haemorrhage and survival in alcoholic cirrhosis. QJM 1998;91:19-25.

31 Patch D, Armonis A, Sabin C, et al. Single portal pressure measurement predicts survival in cirrhotic patients with recent bleeding. Gu 1999:44:264-9.

32 Moitinho E, Escorsell A, Bandi JC, et al. Prognostic value of early measurements of portal pressure in acute variceal bleeding. Gastroenterology 1999;1 17:626-31. 